\title{
Relation between Asphalt, Asphalt Mortar Properties and HMA Performance
}

\author{
Yongzhen Li*, Hao Liang,Feng Jiang,Yu Xia \\ ${ }^{1}$ Shandong Transportation Institute, Jinan, Shandong, 250031, P.R.China \\ ${ }^{2}$ Highway Maintenance Technology Key Laboratory for Transportation Industry, Jinan, Shandong, 250031, P.R.China
}

\begin{abstract}
The relationship among asphalt, mortar and mixture performance was analyzed by grey correlation method by means of asphalt rheological test and hot mix freeze-thaw split test in this paper. The results show that the rheological properties of asphalt as well as asphalt mortar are closely related to HMA performance. Rheological index has a good advantage in explaining HMA pavement diseases. Asphalt stiffness, cohesion, yield stress, rutting coefficient, multiple stress creep and recovery have a high correlation with the strength of the mixture; meanwhile, softening point, normal stress, interface bonding ability of asphalt mortar and volume index of mixture have a high correlation with the water stability of the mixture. In the evaluation of asphalt and asphalt mortar, methods such as stress creep recovery, stress scanning (yield stress, normal stress) and interface bond test should be further proposed and popularized.
\end{abstract}

\section{Introduction}

Hot-mix asphalt concrete (HMA) is a mixture of asphalt and mineral aggregates, previous study always kept more focus on asphalt properties except for aggregate gradation. But in mechanism explanation, many traditional empirical evaluation indexes including penetration, ductility and others show weak relation to pavement performance; this is mainly because traditional evaluation tests cannot fully simulate actual work condition in pavement $[1,2]$. With the development of the evaluation instrument, present researchers began to pay more attention to rheological properties of asphalt, asphalt mortar and other micro-level system, and these properties can be obtained by dynamic shear rheometer (DSR) by simulating different load stress, shear frequency and shear process similar to pavement work condition, among which asphalt performance grading system coming from SHRP project is a typical rheological achievement. Now days, the use of DSR has begun to promote the development of asphalt evaluation technology.

In this paper, three neat asphalts were evaluated by traditional test and rheological experiments; using these three asphalts, HMA mixture were prepared and water stability was evaluated by freeze-thaw splitting test. This test was chosen because it covers two different test conditions, including material splitting strength (RT) and moisture damage characteristic parameter (TSR).Thus, a gray correlation analysis between asphalt properties and $\mathrm{R}_{\mathrm{T}}$, and $\mathrm{TSR} \%$ can be executed for correlation contrast between traditional and rheological indexes.

\section{Material and experiment}

\subsection{Materials}

Three neat asphalts were penetration grade 50,70 and 90 coming from CNOOC and code as ZH50, ZH70 and ZH90 separately, and they satisfied the A-grade requirements in China road specification [3].

HMA mixture was continuous dense gradations of AC-20 type which nominal maximum aggregate size is $19 \mathrm{~mm}$, and for all asphalts ,its optimized asphalt content is $4.2 \%$, the filler-bitumen ratio (FB) is 1.1 which means the proportion of mineral powder (size less than $0.075 \mathrm{~mm}$ ) to effective asphalt in HMA. All mineral aggregates and mineral powder were limestone and met the construction requirement in China road specification [3].

Except for asphalt, a series of asphalt mortars based on neat asphalts were produced with FB value of 1.1. These asphalt mortars consist of neat asphalt and mineral powder which size less than $0.075 \mathrm{~mm}$.

\subsection{Experiment Measurement}

Neat asphalts were evaluated by traditional tests and rheological experiments. The former include penetration, softening point, ductility, viscosity, thin film oven test (TFO) and TFO residue tests according to standard test methods in China highway engineering (JTG E20-2011) [4]. Meanwhile, the adhesion levels between asphalt and aggregate were also obtained by water immersion standard test [4]. These property indexes were shown in Table 1.

*Corresponding author: liyongzhen@sdjtky.cn 
Rheological experiments were realized by Dynamic Shear Rheometer (DSR) and Bending Beam Rheometer (BBR). These rheological indexes include yield stress, normal stress and multiple stress creep and recovery (MSCR), interface bonding coefficient and low temperature creep stiffness $(\mathrm{S})$ and creep rate $(\mathrm{m})$. The above experiments refer to some related disciplines such as AASHTO T313, 315, 316 and TP70; the other designed experiments were explained as following.

(1) Yield stress

Yield stress is the maximum stress, below which material doesn't show a remarkable flow behavior or plastic deformation and just creep slowly [5]. For asphalt, a dynamic stress sweep by DSR can be used to get this parameter. During the measurement, the stress control mode was applied, and the stress was from $0.05 \mathrm{~Pa}$ to $10000 \mathrm{~Pa}$. The diameter of $25 \mathrm{~mm}$ plate the gap of $1 \mathrm{~mm}$ was used. The frequency was set as $10 \mathrm{rad} / \mathrm{s}$. The test temperature was $50^{\circ} \mathrm{C}$. For example, Figure 1 is $\mathrm{ZH} 90$ asphalt stress sweep curves; we can obtain the yield stress $1000 \mathrm{~Pa}$ by the inflection point of phase angle $(\tan \delta)$ tangent and rutting factor $\left(\mathrm{G}^{*} / \sin \delta\right)$. Yield stresses of three neat asphalts were shown in Table.1.

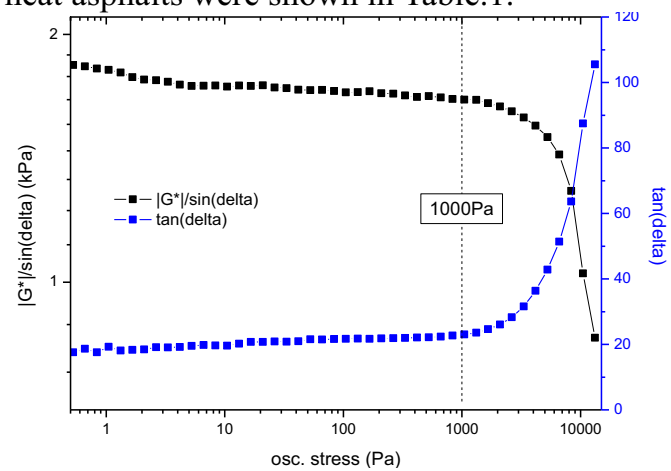

Fig.1 Dynamic stress sweep of ZH 90 petroleum asphalt

(2) Normal stress

When polymer material under shear, normal stress will appear in the vertical direction of the shear stress, and it is a usual property[6]. In present HMA study, some papers have concerned on asphalt migration because of normal stress in actual asphalt pavement, which sometimes lead to some pavement diseases [7]. During the measurement, a time sweep process in DSR was used to collect normal stress, and test temperature was $50^{\circ} \mathrm{C}$, frequency was $10 \mathrm{rad} / \mathrm{s}$ and dynamic stress was $100 \mathrm{~Pa}$. Normal stresss of three neat asphalts were shown in Table.1.

(3) Multiple stress creep and recovery test

This test parameter mainly refer to AASHTO TP70 [8], the evaluation index is average $\%$ recovery at $100 \mathrm{~Pa}$ and $3200 \mathrm{~Pa}$, here coded as \% $\%_{\varepsilon \mathrm{r}}\left(100\right.$, Avg.) and $\%_{\varepsilon \mathrm{r}}(3200$, Avg.).

(4) Interface bonding coefficient of asphalt mortar Asphalt mortar consists of organic asphalt and mineral powder, in which these two substances have different mechanical property and produce an incompatible phase structure, and there would be an interface bonding behavior between asphalt and powder. If this bonding ability is weak, the whole asphalt mortar system would be not stable, and probably crack when load added, then lead to micro-crack and increase the probability of water invasion.

For a blend system of polymer material and inorganic powder, its interface bonding ability can be judged by $\tan \delta$ changes [9]. The equation 1 is one of calculation method, in which B-value is interface bonding coefficient, and it is bigger, bonding ability is big also[10]. In order to obtain this B-value, neat asphalt and asphalt mortars $(\mathrm{FB}=1.1)$ were tested to get $\tan \delta$ values separately, and then calculated them. Here, DSR test condition was $100 \mathrm{~Pa}$ stress, $10 \mathrm{rad} / \mathrm{s}$ frequency, $50{ }^{\circ} \mathrm{C}$ temperature. The final calculated $\mathrm{B}$ values were shown in Table 1.

(Here, $\delta_{\mathrm{c}}$ is blend system phase angle, $\delta_{\mathrm{b}}$ is base material phase angle, and $\varphi$ is the filler volume percent, $\mathrm{B}$ is the interface bonding coefficient.)

For HMA concrete, water stability was evaluated by freeze-thaw splitting test according to standard test methods in China highway engineering (JTG E20-2011) [4].

\section{Gray correlation analysis}

For a random process with a fixed change range, based on gray differential equation, gray correlation analysis can weaken the original data randomness and strengthen its regularity through some special modification; here the original data can be usually smoothed by limited accumulation method [11]. This method is used to evaluate the correlation differences among all influencing factor and decide major effect factors for the random process [12]. The data modification and analysis process is shown in following.

(1) Select a reference data array, and code as $\mathrm{X} 0(\mathrm{t})$, and the comparative data arrays are coded as $\mathrm{Xi}(\mathrm{t})$ $(\mathrm{t}=1,2,3, \ldots, \mathrm{n} ; \mathrm{i}=1,2,3, \ldots, \mathrm{n})$. Each arrays formed a $\mathrm{N}$ dimensional vector in every time such as $\mathrm{Xi}(1) 、 \mathrm{Xi}(2)$, $\mathrm{Xi}(3), \ldots, \mathrm{Xi}(\mathrm{n})$. These arrays are initialized to be non-dimensional, and the following equations are the examples.

$$
\begin{aligned}
& X_{0}=\left\{1, \frac{X_{0}(2)}{X_{0}(1)}, \cdots \cdots, \frac{X_{0}(n)}{X_{0}(1)}\right\} \\
& X_{1}=\left\{1, \frac{X_{1}(2)}{X_{1}(1)}, \cdots \cdots, \frac{X_{1}(n)}{X_{1}(1)}\right\} \\
& X_{n}=\left\{1, \frac{X_{n}(2)}{X_{n}(1)}, \cdots \cdots, \frac{X_{n}(n)}{X_{n}(1)}\right\}
\end{aligned}
$$

(2)Obtain a difference sequence numbers (Di(t)) based on the above initialized data arrays according to equation 5 .

$$
D_{i}(t)=\left|X_{0}(t)-X_{i}(t)\right|
$$

(3)Calculate the minimum difference 
$\min _{i} \min _{t}\left|X_{0}(t)-X_{i}(t)\right|$ and the maximum difference $\max _{i} \max _{t}\left|X_{0}(t)-X_{i}(t)\right|$ in difference sequence numbers.

(4)Calculate correlation degree by equation 6 .

Because $\min _{i} \min _{t}\left|X_{0}(t)-X_{i}(t)\right|$ value is 0 , so we can suppose $\max _{i} \max _{t}\left|X_{0}(t)-X_{i}(t)\right|=\alpha$, and $\beta$ is a resolution coefficient which value is 0.5 . So the equation 6 can be simplified as equation 7 .

$$
\bar{D}_{i}(t)=\frac{\min _{i} \min _{t}\left|X_{0}(t)-X_{i}(t)\right|+\beta \max _{i} \max _{t}\left|X_{0}(t)-X_{i}(t)\right|}{\left|X_{0}(t)-X_{i}(t)\right|+\beta \max _{i} \max _{t}\left|X_{0}(t)-X_{i}(t)\right|}
$$

$$
\bar{D}_{i}(t)=\frac{\alpha \beta}{D_{i}(t)+\alpha \beta}=\frac{0.5 \alpha}{D_{i}(t)+0.5 \alpha}
$$

(5) To calculate the average correlation degree $\gamma$ i by

\begin{tabular}{|c|c|c|c|c|}
\hline Arrays & Data items & $50 \#$ AC20 & 70\#AC20 & $90 \#$ AC20 \\
\hline $\mathrm{X}_{0}$ & Splitting strength $\mathrm{R}_{\mathrm{T}}, \mathrm{MPa}$ & 1.09 & 0.89 & 0.73 \\
\hline $\mathrm{X}_{0}$ & TSR, $\%$ & 90.8 & 86.5 & 82.2 \\
\hline $\mathrm{x}_{1}$ & Penetration@ $25^{\circ} \mathrm{C}, 0.1 \mathrm{~mm}$ & 51 & 63 & 76 \\
\hline $\mathrm{x}_{2}$ & Equivalent brittle point $\mathrm{T}_{1.2},{ }^{\circ} \mathrm{C}$ & -7.1 & -8.9 & -10.1 \\
\hline $\mathrm{x}_{3}$ & Softening point, ${ }^{\circ} \mathrm{C}$ & 49 & 46 & 45 \\
\hline $\mathrm{x}_{4}$ & Ductility@10ㄷ,cm & 39 & 142 & 150 \\
\hline $\mathrm{x}_{5}$ & Viscosity@60 $\mathrm{C}$,Pa.s & 271.5 & 195.5 & 132.5 \\
\hline $\mathrm{x}_{6}$ & Residual penetration ratio@25 $25^{\circ} \mathrm{C}, \%$ & 80 & 82.5 & 85 \\
\hline $\mathrm{x}_{7}$ & Residual ductility@10 $\mathrm{C}, \mathrm{cm}$ & 8 & 15 & 57 \\
\hline $\mathrm{x}_{8}$ & Creep stiffness @-6 $6^{\circ} \mathrm{C}, \mathrm{MPa}$ & 103 & 81.1 & 76.9 \\
\hline $\mathrm{x}_{9}$ & Creep rate @- $-6^{\circ} \mathrm{C}$ & 0.373 & 0.397 & 0.428 \\
\hline $\mathrm{x}_{10}$ & 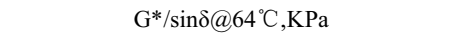 & 1.682 & 1.267 & 0.918 \\
\hline $\mathrm{x}_{11}$ & Yield stress@50ㄷ,Pa & 1573 & 1164 & 1000 \\
\hline $\mathrm{x}_{12}$ & Normal stress @ $50^{\circ} \mathrm{C}, \mathrm{Pa}$ & 11906.6 & 11353.4 & 13061.3 \\
\hline $\mathrm{x}_{13}$ & $\%_{\text {cr }}\left(100\right.$, Avg.) $@ 60^{\circ} \mathrm{C}$ for fresh state, \% & 1.162 & 1.488 & 0.8435 \\
\hline $\mathrm{x}_{14}$ & $\%_{\text {er }}(3200$, Avg. $) @ 60^{\circ} \mathrm{C}$ for fresh state，\% & 0.4134 & 0.1642 & -0.3541 \\
\hline $\mathrm{x}_{15}$ & 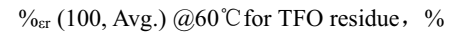 & 4.859 & 4.293 & 3.675 \\
\hline $\mathrm{x}_{16}$ & $\%_{\text {sr }}(3200$, Avg. $) @ 60^{\circ} \mathrm{C}$ for TFO residue, \% & 1.972 & 1.56 & 0.3859 \\
\hline $\mathrm{x}_{17}$ & Adhesion level & 5 & 4.5 & 3 \\
\hline $\mathrm{x}_{18}$ & Void content of HMA, $\%$ & 5.48 & 5.5 & 5.86 \\
\hline $\mathrm{x}_{19}$ & Interface bonding coefficient B & 0.5585 & 0.4433 & 0.4835 \\
\hline
\end{tabular}

Table 1 some physical indexes related to mixture performance

Note: $\mathrm{x}_{1}-\mathrm{x}_{16}$ data arrays are asphalt properties, $\mathrm{x}_{17}$ is the adhesion level from water immersion test, $\mathrm{x}_{19}$ is the interface bonding coefficient of asphalt mortar. equation 8. And this $\gamma \mathrm{i}$ value is the correlation degree between reference array $\mathrm{X} 0$ and the comparative arrays $\mathrm{Xi}$.

$$
\gamma_{i}=\frac{1}{n} \sum_{i=1}^{n} \bar{D}_{i}(t)
$$

In this analysis, we selected splitting strength $\mathrm{Rt}$ and the DSR\% values of three asphalt mixtures as reference data arrays, and select some properties of asphalts, asphalt mortars and mixture as the comparative data arrays (shown in Table 1). Following the above process, the correlation degrees were calculated and shown in Table 2. 
Table 2 Correlation degrees to mixture performance indexes

\begin{tabular}{|c|c|c|c|c|c|}
\hline \multirow{2}{*}{ Order } & \multicolumn{2}{|l|}{ Correlation degree to $\mathrm{R}_{\mathrm{T}}$} & \multicolumn{2}{|l|}{ Correlation degree to TSR } & \multirow{2}{*}{ Order } \\
\hline & Property & $\gamma$ & Property & $\gamma$ & \\
\hline 1 & Creep stiffness @- $6^{\circ} \mathrm{C}, \mathrm{MPa}$ & $98.93 \%$ & Softening point, ${ }^{\circ} \mathrm{C}$ & $99.71 \%$ & $\boldsymbol{\Delta}$ \\
\hline 2 & Yield stress@50 ${ }^{\circ} \mathrm{C}, \mathrm{Pa}$ & $98.88 \%$ & Normal stress@ @50 ${ }^{\circ} \mathrm{C}, \mathrm{Pa}$ & $98.05 \%$ & $\boldsymbol{\Delta}$ \\
\hline 3 & Adhesion level & $98.45 \%$ & Interface bonding coefficient B & $97.96 \%$ & $\boldsymbol{\Delta}$ \\
\hline 4 & \%er (100, Avg.) @60 $6{ }^{\circ} \mathrm{f}$ for TFO residue, \% & $98.45 \%$ & Void content of HMA sample, $\%$ & $97.79 \%$ & $\boldsymbol{\Delta}$ \\
\hline 5 & $\mathrm{G}^{*} / \sin \delta @ 64^{\circ} \mathrm{C}, \mathrm{KPa}$ & $98.13 \%$ & \%вr (100, Avg.) @60 C for TFO residue, \% & $97.75 \%$ & $\nabla$ \\
\hline 6 & Interface bonding coefficient B & $97.86 \%$ & Residual penetration ratio@ $25^{\circ} \mathrm{C}, \%$ & $97.57 \%$ & $\boldsymbol{\Delta}$ \\
\hline 7 & Viscosity@60ㄱ,Pa.s & $97.26 \%$ & Creep stiffness @- $6^{\circ} \mathrm{C}, \mathrm{MPa}$ & $96.70 \%$ & $\nabla$ \\
\hline 8 & Softening point, ${ }^{\circ} \mathrm{C}$ & $96.40 \%$ & Adhesion level & $96.47 \%$ & $\nabla$ \\
\hline 9 & \%яr (3200, Avg.) @60 Cfor TFO residue, \% & $95.47 \%$ & Creep rate $@-6{ }^{\circ} \mathrm{C}$ & $96.44 \%$ & $\boldsymbol{\Delta}$ \\
\hline 10 & $\%$ or (100, Avg.) @6 $60^{\circ} \mathrm{C}$ for fresh state, \% & $95.24 \%$ & Yield stress@50C,Pa & $95.21 \%$ & $\nabla$ \\
\hline 11 & Normal stress @ $50^{\circ} \mathrm{C}, \mathrm{Pa}$ & $94.75 \%$ & $\%$ er (100, Avg.) @ $60^{\circ} \mathrm{C}$ for fresh state, \% & $95.00 \%$ & $\nabla$ \\
\hline 12 & Void content of HMA sample, $\%$ & $94.50 \%$ & $\mathrm{G}^{*} / \sin \delta @ 64^{\circ} \mathrm{C}, \mathrm{KPa}$ & $94.54 \%$ & $\nabla$ \\
\hline 13 & Residual penetration ratio@ $25^{\circ} \mathrm{C}, \%$ & $94.30 \%$ & Viscosity@60ㄱ,Pa.s & $93.74 \%$ & $\nabla$ \\
\hline 14 & Creep rate $@-6{ }^{\circ} \mathrm{C}$ & $93.33 \%$ & Equivalent brittle point $\mathrm{T} 1.2,{ }^{\circ} \mathrm{C}$ & $92.31 \%$ & $\boldsymbol{\Delta}$ \\
\hline 15 & Equivalent brittle point $\mathrm{T} 1.2,{ }^{\circ} \mathrm{C}$ & $89.72 \%$ & \%вr (3200, Avg.) @6 $60^{\circ} \mathrm{C}$ for TFO residue, \% & $92.16 \%$ & $\nabla$ \\
\hline 16 & Penetration@ $25^{\circ} \mathrm{C}, 0.1 \mathrm{~mm}$ & $89.42 \%$ & 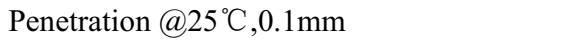 & $91.95 \%$ & / \\
\hline 17 & \%\&r (3200, Avg.) @60 C for fresh state, \% & $85.47 \%$ & \%\&r (3200, Avg.) @60 Cfor fresh state, \% & $82.89 \%$ & l \\
\hline 18 & Residual ductility@10 $\mathrm{C}, \mathrm{cm}$ & $69.55 \%$ & Residual ductility@10 $\mathrm{C}, \mathrm{cm}$ & $70.15 \%$ & / \\
\hline 19 & Ductility@10C,cm & $67.91 \%$ & Ductility@10C,cm & $68.34 \%$ & / \\
\hline
\end{tabular}

Note 1: For the sake of analysis, correlation degrees were arranged in order of size.

Note 2: $\boldsymbol{\Delta}$ represents correlation degree of this property index to mixture performance moves forward after freeze-thaw circle, and

$\nabla$ means the opposite.

\section{Results and discussion}

\subsection{Property contrast between different asphalts}

All test data is described in Table 1. With asphalt penetration grade increases, splitting strength Rt and TSR values of HMA specimen, yield stress, average recovery percent in MSCR test for TFO residue and other indexes decrease, but normal stress and adhesion level increase. It seems to show a relation between HMA performance and component property. For better understanding of this phenomenon, gray correlation analysis is carried according to the above calculation processes.

\subsection{Splitting strength and component property}

Among 19 component properties in Table 2, there are 5 property indexes including creep stiffness, yield stress, adhesion level, TFO residue \%عr (100, Avg.) and rutting factor which have correlation degrees higher than $98 \%$. These factors with lower correlation degrees are penetration, fresh binder \% $\%$ r $(100$, Avg.) and two ductility indexes.

Asphalt mixture is blending system, the strength property of component material will decide the mixture performance; and higher binder's bonding ability will increase better mixture stability. So, some mechanical properties such as yield stress, creep stiffness, creep recovery ratio, rutting factor and adhesion level will have higher correlation degrees to splitting strength. Inside, creep recovery actually represents the cumulative strain of asphalt material under a certain stress level, and this strain behavior will inevitably influence mixture strength in splitting process. But as a same creep recovery process, the $\%_{\varepsilon r}(100$, Avg.) index under $100 \mathrm{~Pa}$ has higher correlation degree than the $\%_{\text {er }}(3200$, Avg.) index under $3200 \mathrm{~Pa}$. Through analysis on yield stress shown in Table 
1, we can see that three asphalts cannot be in linear viscoelastic state and are yielded when load stress is greater than $1600 \mathrm{~Pa}$, and it means the stress of $3200 \mathrm{~Pa}$ make asphalt occurred plastic deformation, thus asphalt isn't stable and produce a weak correlation to splitting strength. Oppositely, the stress of $100 \mathrm{~Pa}$ can ensure asphalt is in stable linear viscosity state, and it constitutes the rationality and stability of contrast among asphalts with different yield stress. In this sense, the multiple stress creep and recovery test process with $3200 \mathrm{~Pa}$ may be not adapted to neat asphalt with low yield stress.

The interface bonding coefficient B of asphalt mortar has higher correlation to $\mathrm{R}_{\mathrm{T}}$ too. $\mathrm{B}$ value represents consolidation ability and should have an inevitable influence on splitting strength. Meanwhile, viscosities, softening point, normal stress and HMA void content also have better correlation degrees higher than $94 \%$.

For the last indexes in Table 2, penetration, ductility and equivalent brittle point have lower correlation with $\mathrm{R}_{\mathrm{T}}$, because these tests cannot simulate a stress or strain condition. Meanwhile, the correlation degrees of TFO residue are higher than in a fresh state.

\subsection{TSR and component property}

In this respect, softening point, normal stress, mortar interface bonding coefficient and HMA void content shown higher correlation degrees to TSR, and this phenomenon is different from $\mathrm{R}_{\mathrm{T}}$. At the same time, the $\%_{\text {rr }}(100$, Avg. $)$ index under $100 \mathrm{~Pa}$ and penetration ratio for TFO residue begin to have a better correlation than in the former process.
As Table 2 shows, after freeze-thaw process, there are 6 evaluation indexes have move forward in correlation order, such as normal stress, interface bonding coefficient B, HMA void content and residue penetration ratio, creep rate and equivalent brittle point. The indexes declining in correlation order are multiple stress creep recovery, creep stiffness, adhesion level, yield stress and rutting factor, which all show mechanical property of material. The last items are still penetration, ductility indexes. Meanwhile, the correlation degrees of TFO residue are higher than in a fresh state.

Broadly speaking, rheological indexes have closer correlation to TSR than traditional indexes, and they can reflect some dynamic information in freeze-thaw test. Figure 1 is the main process of freeze-thawing splitting test, and during this test, a group of HMA samples experience three temperature periods. In water saturation period, specimen water saturability is decided by void content; bigger void content will lead to higher water saturability and increase moisture damage to the asphalt membrane and bonding effect on aggregate surface. In next periods, HMA specimen experience different temperature conditions, and more stresses exist in mixture system because of different thermal properties of aggregate particles, asphalt and asphalt mortar; at the moment, higher creep rate of asphalt and better interface bonding ability of asphalt mortar will improve specimen stability. So these property indexes related to freeze-thaw process should have closer correlation to TSR, and those strength indexes which don't evolve in freeze-thaw process should have lower correlation degree to TSR; this is why some evaluation indexes changed in correlation order.

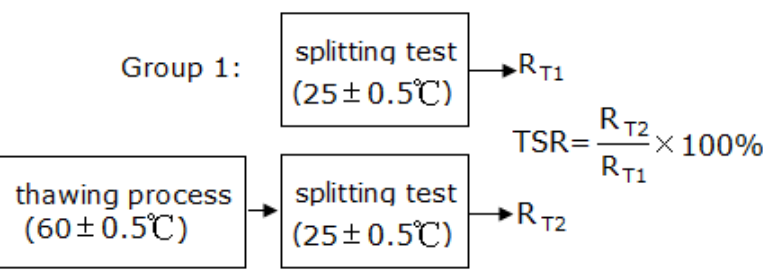

Fig.2 Freeze-thawing splitting test process and temperatures

\section{Application of rheological indexes for HMA pavement disease}

By the above analysis, a conclusion is that rheological properties have closer correlation to HMA performance than traditional indexes, and it is more meaningful to evaluate aging asphalt than fresh state. So, rheological indexes own a better advantage in explaining HMA pavement disease.

Because asphalt mixture consists of mineral aggregate, asphalt and void, inside which asphalt and asphalt mortar have lower yield stress, so, these two material will firstly be destroyed under a load and shear condition. Especially in water environment, because of asphalt yield or weak asphalt mortar structure, asphalt membrane will be broken and water will invade into mixture structure, thus a prone of mixture moisture damage will happen. In this sense, those indexes which reflect material strength and anti-deformation ability should be closely related to mixture performance, for example, creep and recovery ability, rutting factor, creep stiffness and softening point, etc., and these example indexes shown higher correlation to HMA splitting strength.

As a viscoelastic material, asphalt will produce normal stress when load is added [13]. Because of void existing in HMA mixture, the gap between aggregates can be looked as a tube wall, asphalt will flow and migrate by normal stress, and this phenomenon is called Weissenberg effect [14]. Some previous studies shown that different shear stress exist in different level of pavement structure; thus, asphalt in different level will experience different normal stress and could migrate or flow between aggregates in high temperature environment. For example, there is apparently ribbon pattern flushing asphalt existing in pavement section with higher rut depth in high temperature and heavy load 
environment [7].

As a conclusion, better asphalt should be one with high yield stress, low normal stress, and higher elastic recovery ability in high temperature and higher creep rate in low temperature; meanwhile, asphalt mortar should have good interface bonding ability to improve mixture stability; the most important is that HMA mixture should have appropriate void content and structure. Both these features are the premise of a good HMA mixture.

\section{Conclusions}

Rheological properties of asphalt and asphalt mortar have closer correlation to HMA performance than traditional empirical properties, and rheological indexes own better advantage in explaining HMA pavement disease.

In terms of mixture strength, asphalt stiffness, adhesion level, yield stress, rutting factor, multiple stress creep and recovery test have higher correlations than others; but in water stability, softening point, normal stress, interface bonding ability of asphalt mortar and mixture volume index have higher correlations.

In the evaluation of asphalt and asphalt mortar, some DSR methods should be put forward and popularized, such as multiple stress creep and recovery, stress sweep (yield stress, normal stress), interface bonding test,etc.

\section{Acknowledgements}

This work was financially supported by the Shandong Natural Science Foundation (ZR2009FL020) and Shandong Transportation Innovation Foundation (2010Y20)

\section{References}

1. SHEN Jin-an. Asphalt and asphalt mixture pavement performance [M]. Beijing: China Communications Press, 2009

2. Chen J S, Tsai c J. How Good Are Linear Viscoelastic Properties of Asphalt Binder to Predict Rutting and Fatigue Cracking [J]. JMEPEG, 1999, (8):443-449

3. Industry standard of the People's Republic of China. Technical specifications for construction of highway asphalt pavement (JTG F40-2004) [S]. Beijing: China Communications Press, 2005

4. Industry standard of the People's Republic of China. Standard test methods of bitumen and bituminous mixtures for highway engineering (JTG E20-2011) [S]. Beijing: China Communications Press, 2011.

5. Zhou Chi xing. Application of Polymer Rheological experiments. Shanghai :Shanghai Jiaotong University Press, 2003

6. Cui Xue-jun, Cheng Ping, Zhang Hai-tao, etc. Finite element simulation of a test model for interface bonding strength between coating and substrate $[\mathrm{J}]$. Journal of Jilin University
(Engineering and Technology Edition), 2007 , $37(2): 357-361$

7. Zhang Jiupeng, Huang Xiaoming, Zhao Yongli. Asphalt Migration in Rut of Asphalt Pavement and its Viscoelastic Mechanism [J]. Journal of Wuhan University of Technology (Transportation Science \& Engineering), 2008, 32(4):596-606

8. AASHTO TP 70-09. Standard Method of Test for Multiple Stress Creep Recovery (MSCR) Test of Asphalt Binder Using a Dynamic Shear Rheometer (DSR)[S]. 2009

9. Guo Meili. Dynamic thermal mechanical analysis of high polymer and compound material [M]. Beijing: Chemical Industry Press, 2002

10. Ibarra L, Panos D. Dynamic Properties of Thermoplastics Butadiene-Styrene(SBS)and Oxidized Short Carbon Fiber Composite Materials[J]. Journal of Applied Polymer Science, 1998, 67:1819-1826.

11. LIAO Yu-chun, SHI Zhao-hui, HUO Dian. Research on Evaluating Asphalt-Stone Interfacial Bonding Properties Based on Surface Energy Theory [J]. Highway, 2013, (5):94-97

12. Deng Julong. Gray system theory course [M]. Wuhan: Huazhong University of Science and Technology Press, 1990

13. P.Ravindran, K.R.Pajagopal, J.M.Krishnan, etc. An Experimental Investigation into the Influence of Fillers on the Development of Normal Stresses and Stress Relaxation in Asphalt Mixtures Due to Torsion [J]. Particulate Science and Technology, 2007,25:309-325

14. Liu Lixin. Material principle and viscoelastic mechanism for asphalt mixture [M]. Beijing: People Communication Press, 2007 